\title{
Cholecystokinin-mediated pharmacological preconditioning effects on ischemic rat hearts: Possible signaling pathways
}

\author{
Yuan Cheng ${ }^{B}$, Mengzuo $\mathrm{Wu}^{\mathrm{B}}$, Min Liu' ${ }^{C}$, Birong Zhou ${ }^{C}$, Xianhe Lin ${ }^{D}$, Bangning Wang ${ }^{\mathrm{A}, \mathrm{E}, \mathrm{F}}$ \\ Department of Cardiology, The First Affiliated Hospital of Anhui Medical University, Hefei, China \\ A - research concept and design; $B$ - collection and/or assembly of data; $C$ - data analysis and interpretation; \\ $D$ - writing the article; $E$ - critical revision of the article; $F$ - final approval of the article
}

Address for correspondence

Bangning Wang

E-mail: wangbangning453@sina.com

Funding sources

None declared

Conflict of interest

None declared

Received on March 18, 2021

Reviewed on May 28, 2021

Accepted on June 10, 2021

Published online on September 10, 2021

Cite as

Cheng Y, Wu M, Liu M, Zhou B, Lin X, Wang B.

Cholecystokinin-mediated pharmacological preconditioning

effects on ischemic rat hearts: Possible signaling pathways.

Adv Clin Exp Med. 2021;30(11):1157-1165.

doi:10.17219/acem/138745

DOI

10.17219/acem/138745

Copyright

Copyright by Author(s)

This is an article distributed under the terms of the

Creative Commons Attribution 3.0 Unported (CC BY 3.0)

(https://creativecommons.org/licenses/by/3.0/)

\begin{abstract}
Background. Cholecystokinin (CCK-8) has been shown to exhibit pharmacological preconditioning and cardioprotective effects. However, the molecular mechanisms involved in CCK-8-induced pharmacological preconditioning have not yet been clarified.

Objectives. The current study explored the molecular mechanisms involved in CCK-8-mediated pharmacological preconditioning effects on ischemic rat hearts.

Materials and methods. Pharmacological preconditioning was induced in male Wistar rats by administration of CCK-8 $(20 \mu \mathrm{g} / \mathrm{kg}) 24 \mathrm{~h}$ before heart isolation. The PI3K inhibitor LY294002 (10 mg/kg and $20 \mathrm{mg} / \mathrm{kg})$ and the HIF-1a inhibitor $Y(-1(1 \mathrm{mg} / \mathrm{kg}$ and $2 \mathrm{mg} / \mathrm{kg})$ were administered $30 \mathrm{~min}$ before the administration of CCK-8. The hearts were subjected to ischemia-reperfusion (IR) injury using a Langendorff apparatus. Myocardial injury was quantified by measuring the release of LDH-1, CK-MB and CTnT. The levels of HIF-1a and $p$-Akt expression and the ratio of $p$-GSK-3B/GSK-3B, were assessed in the heart homogenates.
\end{abstract}

Results. Pharmacological preconditioning with CCK-8 reduced IR-induced increases in the release of $L D H$,

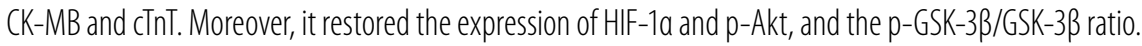
However, administration of LY294002 or YC-1 with CCK-8 significantly abolished the cardioprotective effects of pharmacological preconditioning. The PI3K and HIF-1a inhibitors also abolished the effects of CCK-8 preconditioning on HIF-1a, p-Akt and p-GSK-3B/GSK-3B.

Conclusions. Based on these findings, it may be concluded that the molecular mechanisms participating in CCK-8-induced pharmacological preconditioning involve HIF-1a, PI3K, Akt, and GSK-3B signaling pathways.

Key words: ischemia, reperfusion, LY294002, cholecystokinin, pharmacological preconditioning 


\section{Background}

Interruption of blood flow in the form of ischemia induces severe heart injury, and early restoration of blood flow is essential to salvage ischemic heart. Thrombolysis or angioplasty is typically employed in clinical settings to restore the blood supply to ischemic heart. ${ }^{1}$ However, reperfusion of the ischemic heart itself produces myocardial injury, which is referred to as "reperfusion injury". ${ }^{2}$ Therefore, the term "ischemia-reperfusion-induced myocardial injury" is used to denote myocardial injury that occurs during ischemia and reperfusion (IR). At present, there are no well-established pharmacological agents to prevent IR-induced heart injury. Accordingly, there is a need to find new interventions/pharmacological agents that can limit or prevent IR-induced myocardial injury.

Ischemic preconditioning is a novel technique that renders the heart less vulnerable to prolonged ischemiareperfusion injury by prior exposure of the heart to short episodes of IR. ${ }^{3}$ Researchers have extrapolated the concept of ischemic preconditioning in the form of pharmacological preconditioning, in which short episodes of ischemia are induced by pharmacological agents. ${ }^{4,5}$ Several studies have shown the usefulness of pharmacological preconditioning in conferring resistance to various tissues and organs, ${ }^{6}$ including the heart. ${ }^{7}$

Cholecystokinin (CCK-8) is a neuropeptide secreted by enteroendocrine cells of the duodenum. ${ }^{8}$ Preclinical studies have shown potential beneficial effects of CCK-8 distinct from its typical gastrointestinal effects related to satiety and food intake. ${ }^{9}$ Specifically, CCK-8 has been shown to affect anxiety, ${ }^{10}$ pain, ${ }^{11}$ spatial memory ability, ${ }^{12}$ and IR-induced liver injury. ${ }^{13}$ Furthermore, a recent study reported an association of CCK-8 with reduction of apoptosis in IR-induced renal injury. ${ }^{14}$ Based on the findings of studies conducted in animals, CCK- 8 may also exert beneficial effects in humans. However, there are insufficient clinical studies proving the usefulness of CCK-8 in humans. In continuation of preclinical studies, CCK-8 has been shown to influence pathophysiological states of the heart through CCK-1 and CCK-2 receptors. ${ }^{15}$ For example, CCK- 8 has been shown to attenuate myocardial fibrosis following ischemia-reperfusion injury. ${ }^{16} \mathrm{~A}$ previous study documented that exogenous administration of CCK-8 exhibits pharmacological preconditioning and produces cardioprotective effects against IR injury. ${ }^{17}$ However, the molecular mechanisms involved in CCK-8-induced pharmacological preconditioning have not been explored.

Hypoxia-inducible factor $1-\alpha$ (HIF- $1 \alpha)$ is a transcriptional factor that is reported to play an important role in the cardioprotective effects of different forms of preconditioning. ${ }^{18,19}$ Phosphoinositide 3-kinase (PI3K), protein kinase $B(A k t)$, and glycogen synthase kinase- $3 \beta$ (GSK-3 $\beta$ ) also play important roles in conferring cardioprotection during ischemic, remote and pharmacological preconditioning. ${ }^{20,21}$ Considering the significant role of these signaling pathways in different types of preconditioning-induced cardioprotection, we attempted to explore the role of the HIF-1 $\alpha$, PI3K, Akt, and GSK-3 $\beta$ signaling pathways in CCK-8-induced pharmacological preconditioning on IR model rat hearts.

\section{Objectives}

The present study aimed to investigate the role of the HIF- $1 \alpha$, PI3K, Akt, and GSK-3 $\beta$ signaling pathways in CCK-8-induced pharmacological preconditioning on IR model rat hearts.

\section{Materials and methods}

\section{Drugs and animals}

Three-month-old male Wistar albino rats weighing 210-240 g were used in this study. The animals were fed a normal pellet diet containing fiber $(5 \%)$, protein $(20 \%)$ and fat (5-10\%). Ultraviolet radiation-treated water was provided in bottles for drinking purposes. The animals were exposed to $12 \mathrm{~h}$ of light and $12 \mathrm{~h}$ of dark at $25 \pm 2^{\circ} \mathrm{C}$ and $55-60 \%$ relative humidity. The doses of CCK- $8,{ }^{17}$ PI3K inhibitor LY294002 22,23 and HIF-1 inhibitor YC-1 ${ }^{24}$ were determined based on the previous literature. Kits for the quantification of lactate dehydrogenase 1 (LDH-1), the $\mathrm{MB}$ isoform of creatine kinase (CK-MB), cardiac troponins (cTnT), HIF-1 $\alpha$, p-Akt, and p-GSK-3 $\beta$ were procured from MyBioSource, Inc. (San Diego, USA).

\section{Approval of animal experiments}

The experiments were approved by the Animal Ethical Committee of The First Affiliated Hospital of Anhui Medical University, Hefei, China (approval No. 202103050053).

\section{Pharmacological preconditioning}

Pharmacological preconditioning was induced by administering a single dose of CCK-8 $(20 \mu \mathrm{g} / \mathrm{kg})$ intravenously (i.v.), $24 \mathrm{~h}$ before isolating the hearts. ${ }^{17}$

\section{Ischemia-reperfusion injury}

After $24 \mathrm{~h}$ of pharmacological preconditioning, rats were sacrificed by an overdose of $4.5 \%$ isoflurane (gaseous anesthetic agent) and the hearts were quickly isolated. Heparin (1000 units $/ \mathrm{kg}$ ) was administered through the intraperitoneal (i.p.) route $30 \mathrm{~min}$ before sacrificing the rats, to prevent clot formation in the coronary arteries. The isolated hearts were perfused with Krebs-Henseleit $(\mathrm{KH})$ solution (118 mM NaCl, $4.7 \mathrm{mM} \mathrm{KCl,} 1.2 \mathrm{mM} \mathrm{MgSO}_{4}, 1.25 \mathrm{mM}$ 
$\mathrm{CaCl}_{2}, 1.2 \mathrm{mM} \mathrm{KH}_{2} \mathrm{PO}_{4}, 25 \mathrm{mM} \mathrm{NaHCO}_{3}$, and $11 \mathrm{mM}$ glucose, $\mathrm{pH}=7.4$ ) at $37^{\circ} \mathrm{C}$ using a Langendorff system (emka TECHNOLOGIES, Paris, France). Perfusion was stopped for $30 \mathrm{~min}$ to induce global ischemia to the heart. Thereafter, the flow of $\mathrm{KH}$ was restored for $120 \mathrm{~min}$ to institute reperfusion. ${ }^{25,26}$

\section{Quantitative assessment of myocardial injury}

The extent of IR-induced myocardial injury was quantified by measuring the release of 3 heart-specific biochemicals, namely LDH-1, CK-MB and cTnT, in the coronary effluent, using commercially available kits. The measurement of LDH-1 was performed using lithium L-lactate and $\mathrm{NAD}^{+}$to yield pyruvic acid and a reduced form of nicotinamide adenine dinucleotide (NADH); absorbance was then measured at $340 \mathrm{~nm}$ using a spectrophotometer (Cary 60; Agilent Technologies, Santa Clara, USA). LDH-1 was quantified as enzymatic activity recorded in IU/L. The quantification of CK-MB was performed by adding adenosine diphosphate (ADP) to the sample (containing CK-MB) to obtain ATP, which then reacted with glucose in the presence of hexokinase. Thereafter, nicotinamide adenine dinucleotide phosphate $\left(\mathrm{NADP}^{+}\right)$and glucose6-phosphate dehydrogenase were added to generate nicotinamide adenine dinucleotide phosphate (NADPH), and the absorbance was determined at $340 \mathrm{~nm}$ using a spectrophotometer (Cary 60; Agilent Technologies). Like LDH-1, CK-MB was also quantified as enzymatic activity in IU/L. The cTnT levels in the coronary effluent were quantified using a sandwich enzyme-linked immunosorbent assay (ELISA) kit with a cTnT antibody (capture antibody) precoated microplate. The addition of a sample containing cTnT to the wells led to the binding of cTnT to the capture antibody. Next, detection reagent A (biotin-conjugated antibody), detection reagent $B$ (avidin-conjugated horseradish peroxidase (HRP)) and tetramethylbenzidine (a substrate of HRP) were added to yield a color, which was measured at $450 \mathrm{~nm}$ using an ELISA reader (BioTek, Winooski, USA).

\section{Quantification of HIF-1a, p-Akt and p-GSK-3 $\beta$}

After 120 min of reperfusion, the hearts were removed and homogenized in phosphate-buffered saline (PBS) solution $\left(137 \mathrm{mM} \mathrm{NaCl}, 2.7 \mathrm{mM} \mathrm{KCl}, 10 \mathrm{mM} \mathrm{Na}_{2} \mathrm{HPO}_{4}\right.$, $1.8 \mathrm{mM} \mathrm{KH_{2 }} \mathrm{PO}_{4}, \mathrm{pH}=7.4$ ) for $15 \mathrm{~min}$ in a refrigerated microtube tissue homogenizer at $4{ }^{\circ} \mathrm{C}$ (Thomas Scientific, Swedesboro, USA) to obtain the homogenate. The homogenate was centrifuged (Beckman Coulter Life Sciences, Indianapolis, USA) at $5000 \mathrm{~g}$ for $10 \mathrm{~min}$ at $4^{\circ} \mathrm{C}$ to obtain clear supernatant, which was then employed for biochemical estimations. Using the heart homogenate supernatants, the expression of HIF- $1 \alpha$, p-Akt and p-GSK-3 $\beta /$ GSK-3 $\beta$ was quantified using commercially available ELISA kits.

\section{Experimental protocol}

For this study, 7 groups, each containing 8 animals, were used. The animals were randomly assigned to the following groups: 1) non-ischemic group, in which the hearts were isolated for biochemical estimation of HIF-1 $\alpha, \mathrm{p}-\mathrm{Akt}$ and p-GSK-3 $\beta / G S K-3 \beta ; 2$ ) IR injury group, in which hearts were subjected to $30 \mathrm{~min}$ of ischemia and $120 \mathrm{~min}$ of reperfusion; 3) CCK-8 pharmacological preconditioning group; 4 and 5) LY294002 in CCK-8 pharmacological preconditioning group, in which LY294002 (10 and $20 \mathrm{mg} / \mathrm{kg}$ ) was administered before CCK- 8 preconditioning; and 6 and 7) YC-1 in CCK-8 pharmacological preconditioning groups, in which YC-1 (1 and $2 \mathrm{mg} / \mathrm{kg}$, i.p.) was administered before CCK- 8 preconditioning.

\section{Statistical analyses}

Statistical analyses were performed using GraphPad Prism v. 8 (GraphPad Software, San Diego, USA). Data are reported as the mean \pm standard deviation (SD). A normality test was conducted to check the appropriateness of applying analysis of variance (ANOVA). After passing the normality test, the results for LDH-1, CK-MB and cTnT were analyzed with two-way ANOVA. The results of all other parameters were analyzed using one-way ANOVA. These analyses were followed by Tukey's post hoc test. The results of parametric tests are represented as figures. The data were also analyzed using non-parametric tests (Table 1,2), namely the Kruskal-Wallis test (for biochemical parameters) and Friedman's test (for heart injury-specific parameters), followed by Dunn's post hoc test. Statistical significance was fixed at $\mathrm{p}<0.05$.

\section{Results}

\section{Influence of CCK-8 pharmacological preconditioning on IR-induced myocardial injury}

There was a significant increase in the release of heartspecific biochemical markers, namely LDH-1 (Fig. 1), CK-MB (Fig. 2) and cTnT (Fig. 3) in the coronary effluent, in response to $30 \mathrm{~min}$ of ischemia and $120 \mathrm{~min}$ of reperfusion. There was an approximately sixteen-fold increase in LDH-1, 8-fold increase in CK-MB and 12-fold increase in $\mathrm{CTnT}$ release during the reperfusion phase in comparison to non-ischemic hearts. The increased release of these biochemicals in the coronary effluent suggests a significant increase in IR injury to the heart. Notably, pharmacological preconditioning in the form of CCK-8 administration $24 \mathrm{~h}$ before ischemic injury significantly attenuated the release of LDH-1, CK-MB and CTnT in the coronary effluent. In CCK-8-preconditioned rats, the increase in heart injury biomarkers was reduced, i.e., eight-fold increase for LDH-1, 
Table 1. Effect of different interventions on the heart injury parameters in isolated heart. Values are given as median (interquartile range (IQR)). The analysis was done using Friedman's test with Dunn's post hoc analysis

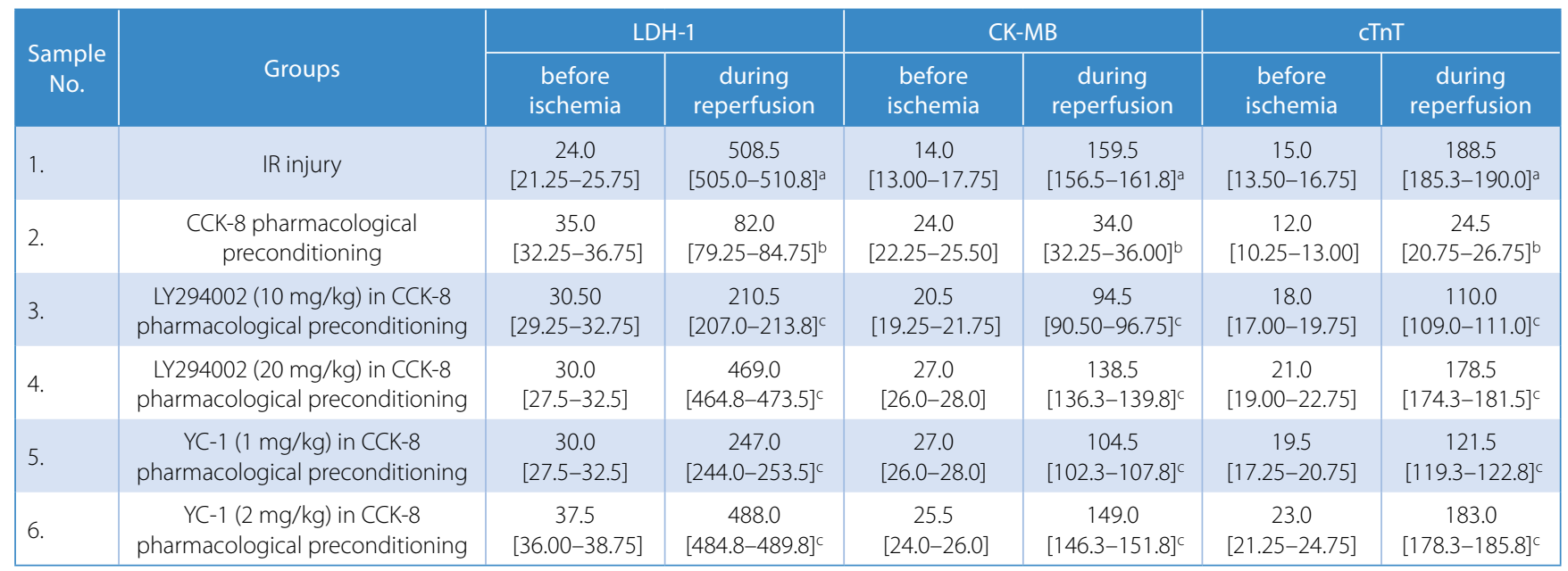

${ }^{a} p<0.05$ compared to results before ischemia; ${ }^{b} p<0.05$ compared to results after IR injury after reperfusion; ${ }^{c} p<0.05$ compared to results after CCK-8 preconditioning; IR - ischemia-reperfusion; CCK-8 - cholecystokinin.

Table 2. Effect of different interventions on biochemical parameters in isolated rat hearts. The data were analyzed using Kruskal-Wallis test and post hoc analysis was done using Dunn's multiple comparison test. Values are given as median (interquartile range (IQR)).

\begin{tabular}{|c|c|c|c|c|}
\hline $\begin{array}{l}\text { Sample } \\
\text { No. }\end{array}$ & Groups & HIF-1a & $\mathrm{p}-\mathrm{Akt}$ & p-GSK-3 $\beta / G S K-3 \beta$ ratio \\
\hline 1. & non-ischemic & 100.0 [99.25-100.0] & $100.0[99.25-100.0]$ & $1.0[0.91-1.1]$ \\
\hline 2. & IR injury & $46.5[43.5-48.0]^{\mathrm{a}}$ & $46.5[43.5-48.0]^{a}$ & $0.31[0.29-0.34]^{b}$ \\
\hline 3. & $\begin{array}{l}\text { CCK-8 pharmacological } \\
\text { preconditioning }\end{array}$ & $88.5[87.0-92.75]^{b}$ & $88.5[87.0-92.75]^{b}$ & $0.90[0.88-0.92]^{b}$ \\
\hline 4. & $\begin{array}{l}\text { LY294002 (10 mg/kg) in CCK-8 } \\
\text { pharmacological preconditioning }\end{array}$ & $69.50[68.25-70.75]^{c}$ & $69.5[68.25-70.25]^{c}$ & $0.74[0.72-0.76]^{c}$ \\
\hline 5. & $\begin{array}{l}\text { LY294002 (20 mg/kg) in CCK-8 } \\
\text { pharmacological preconditioning }\end{array}$ & $56.0[54.25-57.0]^{c}$ & $56.0[54.2-57.0]^{c}$ & $0.56[0.53-0.58]^{c}$ \\
\hline 6. & $\begin{array}{l}\text { YC-1 }(1 \mathrm{mg} / \mathrm{kg}) \text { in CCK-8 } \\
\text { pharmacological preconditioning }\end{array}$ & $64.0[63.0-65.75]^{c}$ & $64.0[63.0-65.75]^{c}$ & $0.64[0.61-0.67]^{c}$ \\
\hline 7. & $\begin{array}{l}\text { YC-1 }(2 \mathrm{mg} / \mathrm{kg}) \text { in CCK-8 } \\
\text { pharmacological preconditioning }\end{array}$ & $52.5[52.0-55.0]^{c}$ & $52.5[52.0-55.0]^{c}$ & $0.43[0.37-0.44]^{c}$ \\
\hline
\end{tabular}

${ }^{a} \mathrm{p}<0.05$ compared to results before ischemia; ${ }^{b} p<0.05$ compared to results after IR injury after reperfusion; ${ }^{c} p<0.05$ compared to results after CCK-8 preconditioning; IR - ischemia-reperfusion; CCK-8 - cholecystokinin.

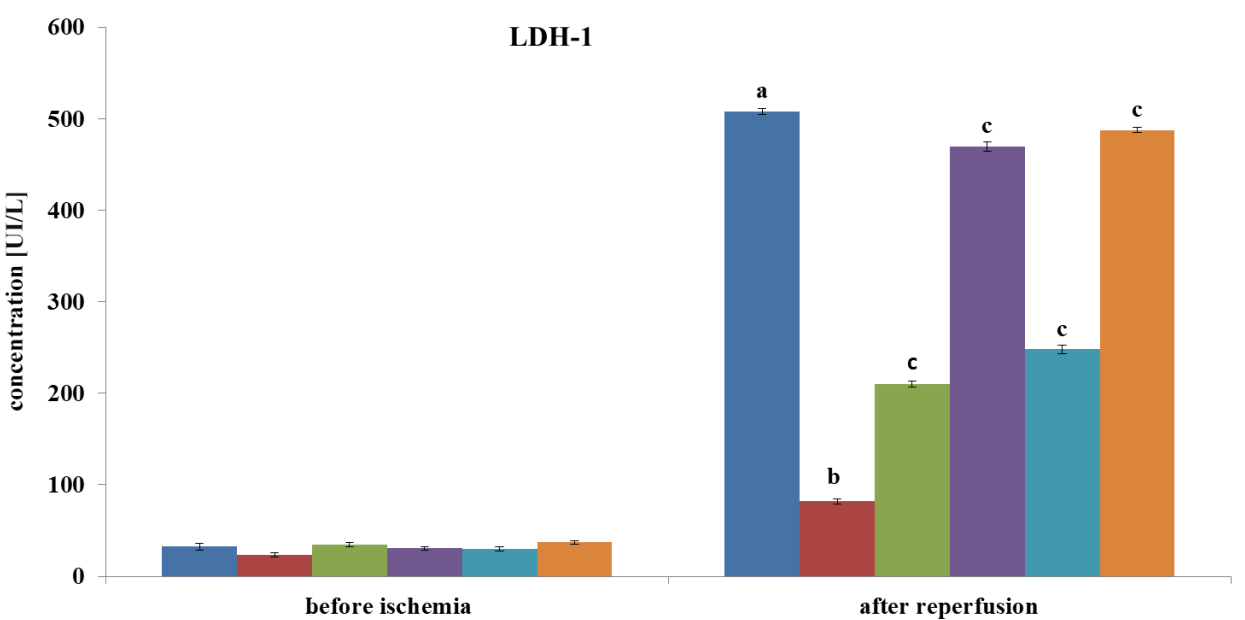

Fig. 1. Influence of cholecystokinin (CCK-8) preconditioning and other interventions on the release of $\mathrm{LDH}-1$ in the coronary effluent

Values are given as mean \pm SD; ANOVA results: $F(1,84)=984.2$ for time, $F(5,84)=453.9$ for treatment, $n=8$ $\mathrm{p}<0.001 ; \mathrm{a}-\mathrm{p}<0.05$ compared to before ischemia; $b-p<0.05$ compared to IR injury after reperfusion; $c-p<0.05$ compared to CCK-8 preconditioning; IR - ischemia-reperfusion; SD - standard deviation; ANOVA - analysis of variance. 


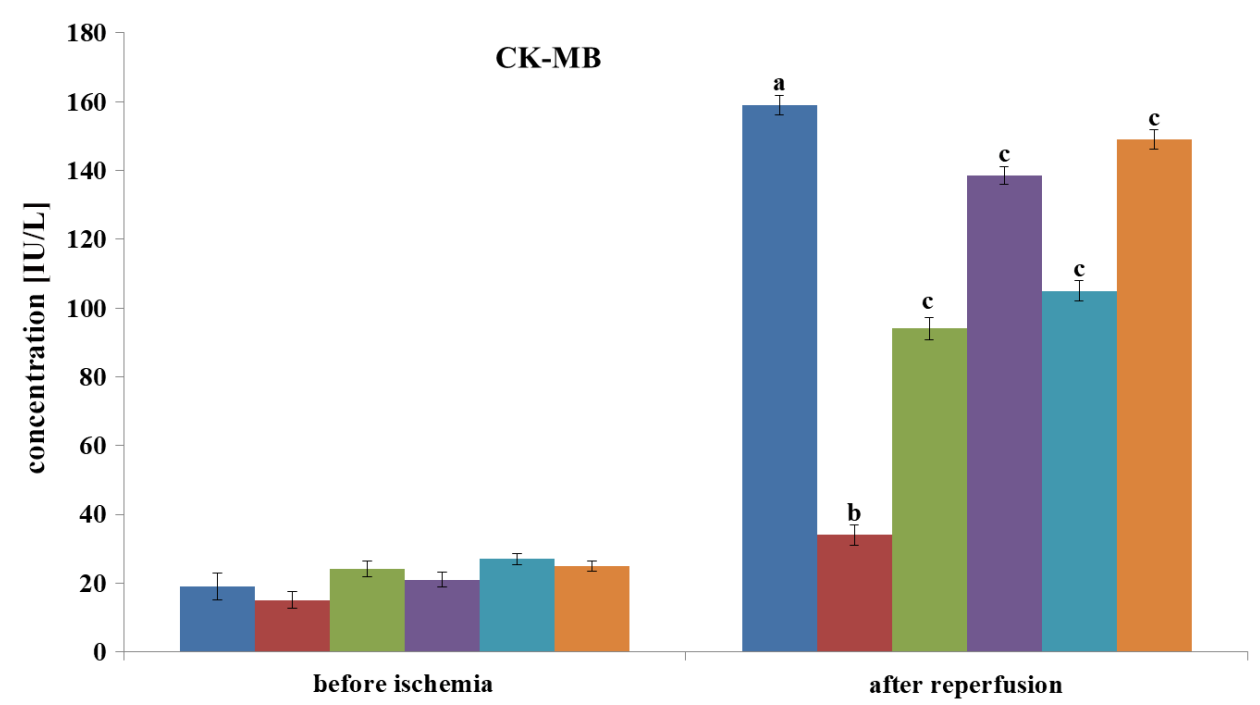

IR injury

๓CCK-8 preconditioning and LY294002 (10 mg/kg) $\quad$ CCK-8 preconditioning and LY294002 (20 mg/kg) nCCK-8 preconditioning and YC-1 $(1 \mathrm{mg} / \mathrm{kg})$

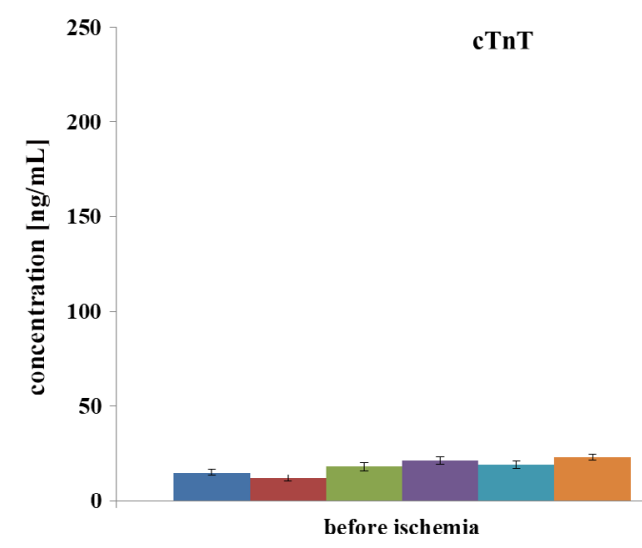

IR injury

CCK-8 preconditioning and LY294002 $(10 \mathrm{mg} / \mathrm{kg})$

๓CCK-8 preconditioning and YC-1 $(1 \mathrm{mg} / \mathrm{kg})$

120

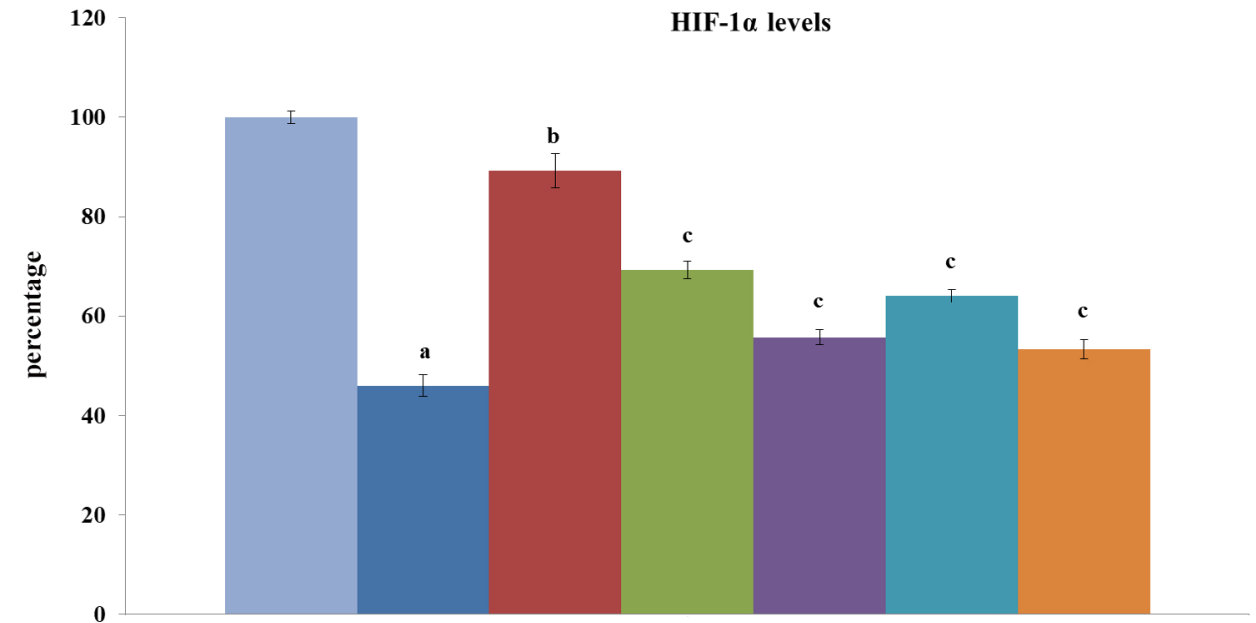

non-ischemic

- CCK-8 preconditioning

口 CCK-8 preconditioning and LY294002 (20 mg/kg)

aCK-8 preconditioning and YC-1 (2 mg/kg)
Fig. 2. Influence of cholecystokinin (CCK-8) preconditioning and other interventions on the release of CK-MB in the coronary effluent

Values are given as mean \pm SD; ANOVA results: $F(1,84)=783.1$ for time, $F(5,84)=395.6$ for treatment, $n=8$, $\mathrm{p}<0.001 ; \mathrm{a}-\mathrm{p}<0.05$ compared to before ischemia; $b-p<0.05$ compared to IR injury after reperfusion; $\mathrm{c}-\mathrm{p}<0.05$ compared to CCK-8 preconditioning; IR - ischemia-reperfusion; SD - standard deviation; ANOVA - analysis of variance.

Fig. 3. Influence of cholecystokinin (CCK-8) preconditioning and other interventions on the release of cTnT in the coronary effluent

Values are given as mean $\pm S D$; ANOVA results: $F(1,84)=812.8$ for time, $F(5,84)=412.7$ for treatment, $n=8$, $p<0.001 ; a-p<0.05$ compared to before ischemia; $b-p<0.05$ compared to IR injury after reperfusion; $\mathrm{c}-\mathrm{p}<0.05$ compared to CCK-8 preconditioning; IR - ischemia-reperfusion; SD - standard deviation; ANOVA - analysis of variance.

Fig. 4. Influence of cholecystokinin (CCK-8) preconditioning and other interventions on ischemia-reperfusioninduced changes in the expression of HIF-1a

Values are reported as mean $\pm \mathrm{SD}$; ANOVA results: $F(6,49)=634.8, n=8$, $\mathrm{p}<0.001 ; \mathrm{a}-\mathrm{p}<0.05$ compared to non-ischemic; $b-p<0.05$ compared to IR injury; $\mathrm{c}-\mathrm{p}<0.05$ compared to CCK-8 preconditioning; IR - ischemiareperfusion; $\mathrm{SD}$ - standard deviation; ANOVA - analysis of variance. 

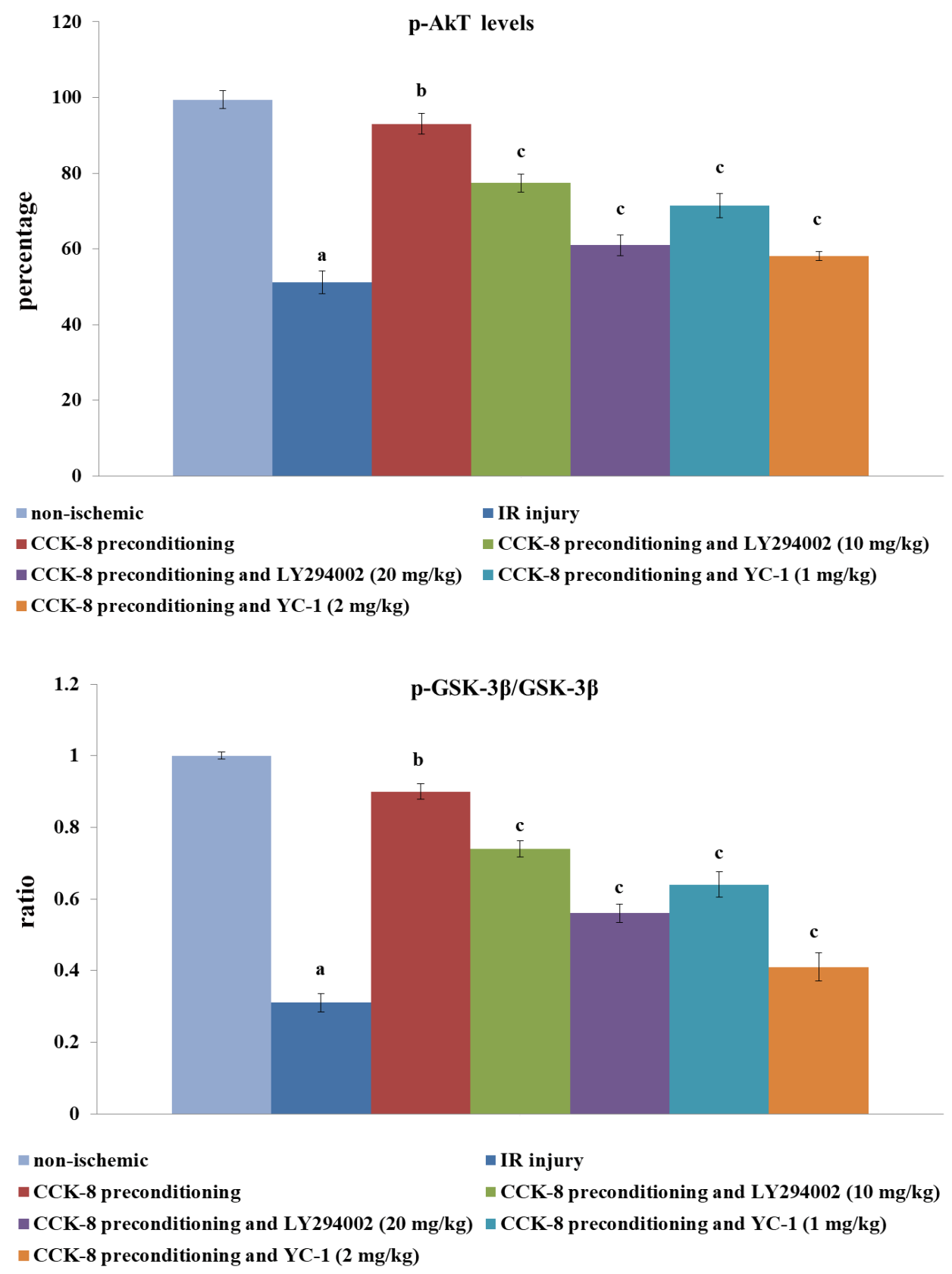

Fig. 5. Influence of cholecystokinin (CCK-8) preconditioning and other interventions on IR-induced changes in the p-Akt levels

Values are given as mean $\pm \mathrm{SD}$; ANOVA results: $F(6,49)=530.1, n=8$, $p<0.001 ; a-p<0.05$ compared to non-ischemic; $b-p<0.05$ compared to IR injury; $c-p<0.05$ compared to CCK-8 preconditioning; IR - ischemiareperfusion; SD - standard deviation; ANOVA - analysis of variance.
Fig. 6. Influence of cholecystokinin (CCK-8) preconditioning and other interventions on IR-induced changes in the $p-G S K-3 \beta / G S K-3 \beta$ ratio in the heart homogenates

Values are given as mean \pm SD; ANOVA results: $\mathrm{F}(6,49)=785.3, \mathrm{n}=8$, $p<0.001 ; a-p<0.05$ compared to non-ischemic; $b-p<0.05$ compared to IR injury; $\mathrm{c}-\mathrm{p}<0.05$ compared to CCK-8 preconditioning; IR - ischemiareperfusion; SD - standard deviation; ANOVA - analysis of variance. four-fold increase for CK-MB, and seven-fold increase for cTnT. Overall, the parameters were nearly two-fold lower than in the IR injury group. This result suggests that CCK-8 produced pharmacological preconditioning and significantly protected the rat hearts from IR injury.

\section{Influence of CCK-8 pharmacological preconditioning on IR-induced biochemical changes in the heart}

Apart from attenuating heart injury, pharmacological preconditioning with CCK-8 prevented ischemia-reperfusion-induced changes in the expression levels of the biochemical markers such as HIF-1 $\alpha$, p-Akt and p-GSK-3 $\beta$. In IR-subjected rats, there was a significant decrease in the expression of HIF-1 $\alpha$ (Fig. 4) and p-Akt (Fig. 5), and in $\mathrm{p}-\mathrm{GSK}-3 \beta / \mathrm{GSK}-3 \beta$ ratio (Fig. 6) in comparison to normal, non-ischemic hearts. In the IR group, the expression of HIF- $1 \alpha$ in hearts was reduced 2.16-fold, the expression of p-Akt 1.94-fold and the p-GSK-3 $\beta /$ GSK-3 $\beta$ ratio 3.1-fold in comparison to non-ischemic hearts. However, pharmacological preconditioning with CCK-8 led to significant restoration of HIF- $1 \alpha$ and p-Akt expression and p-GSK-3 $\beta /$ GSK-3 $\beta$ ratio in the heart homogenates. In CCK-8-preconditioned hearts, the expression of HIF-1 $\alpha$ in hearts was reduced 1.2-fold, the expression of p-Akt 1.1-fold and the $\mathrm{p}-\mathrm{GSK}-3 \beta / \mathrm{GSK}-3 \beta$ ratio 1.4 -fold. Thus, there was an approximately two-fold greater increase in the above biochemical parameters in the CCK-8 preconditioning group compared to the IR injury group. 


\section{Influence of LY294002 and YC-1 on CCK-8 pharmacological preconditioning-induced changes in IR-subjected rat hearts}

In light of the significant increase in the expression of HIF- $1 \alpha$ and p-Akt in CCK-8 preconditioning-subjected rat hearts, the influence of LY294002 and YC-1 on CCK-8-induced changes was explored. Administration of LY294002 (PI3K inhibitor) or YC-1 (HIF-1 $\alpha$ inhibitor) prior to CCK-8 preconditioning significantly abolished CCK-8-induced cardioprotective effects in IR-subjected rat hearts. There was a significant and dose-dependent increase in the levels of LDH-1 (Fig. 1), CK-MB (Fig. 2) and CTnT (Fig. 3) in rat hearts treated with LY294002 $(10 \mathrm{mg} / \mathrm{kg}$ and $20 \mathrm{mg} / \mathrm{kg})$ and $\mathrm{YC}-1(1 \mathrm{mg} / \mathrm{kg}$ and $2 \mathrm{mg} / \mathrm{kg})$. Compared to CCK-8 preconditioning, administration of LY294002 led to a 2.56 -fold $(10 \mathrm{mg} / \mathrm{kg})$ and 5.72 -fold $(20 \mathrm{mg} / \mathrm{kg})$ increase in LDH-1 release; 2.76 -fold $(10 \mathrm{mg} / \mathrm{kg})$ and 4.07-fold (20 mg/ $\mathrm{kg})$ increase in CK-MB release; and 4.58 -fold $(10 \mathrm{mg} / \mathrm{kg})$ and 7.42 -fold $(20 \mathrm{mg} / \mathrm{kg})$ increase in $\mathrm{c} T n \mathrm{~T}$ release during the reperfusion phase. Similarly, in comparison to CCK-8 preconditioning, administration of YC-1 led to a 3.02 -fold ( $1 \mathrm{mg} / \mathrm{kg}$ ) and 5.94-fold $(2 \mathrm{mg} / \mathrm{kg})$ increase in LDH-1 release; 3.08 -fold $(1 \mathrm{mg} / \mathrm{kg})$ and 4.38 fold ( $2 \mathrm{mg} / \mathrm{kg}$ ) increase in CK-MB release; and 5.04-fold $(1 \mathrm{mg} / \mathrm{kg})$ and 7.58 -fold $(2 \mathrm{mg} / \mathrm{kg})$ increase in cTnT release during the reperfusion phase. These results indicate that higher doses of LY294002 (20 mg/kg) and YC-1 (2 mg/kg) almost completely abolished the effects of CCK-8 preconditioning, and that the effects in those groups were comparable to the IR injury group.

Moreover, there was a significant decrease in the levels of HIF-1 $\alpha$ (Fig. 4) and p-Akt expression (Fig. 5) and in $\mathrm{p}$-GSK-3 $\beta /$ GSK-3 $\beta$ ratio (Fig. 6) in the heart homogenates in LY294002 and YC-1-administered rats. In comparison to CCK-8 preconditioning, administration of LY294002 led to a 1.28 -fold $(10 \mathrm{mg} / \mathrm{kg})$ and 1.60 -fold $(20 \mathrm{mg} / \mathrm{kg})$ decrease in HIF- $1 \alpha ; 1.20$-fold $(10 \mathrm{mg} / \mathrm{kg})$ and 1.52 -fold $(20 \mathrm{mg} / \mathrm{kg})$ decrease in p-Akt; and 1.21-fold $(10 \mathrm{mg} / \mathrm{kg})$ and 1.60 -fold $(20 \mathrm{mg} / \mathrm{kg})$ decrease in $\mathrm{p}-\mathrm{GSK}-3 \beta / \mathrm{GSK}-3 \beta$ ratio. Administration of YC-1 led to a 1.39 -fold $(1 \mathrm{mg} / \mathrm{kg})$ and 1.67 -fold $(2 \mathrm{mg} / \mathrm{kg})$ decrease in HIF- $1 \alpha ; 1.30$-fold $(1 \mathrm{mg} / \mathrm{kg})$ and 1.60 fold $(2 \mathrm{mg} / \mathrm{kg})$ decrease in $\mathrm{p}$-Akt; and 1.40-fold $(1 \mathrm{mg} / \mathrm{kg})$ and 2.19 -fold $(2 \mathrm{mg} / \mathrm{kg})$ decrease in $\mathrm{p}-$ GSK-3 $\beta /$ GSK-3 $\beta$ ratio. Similar to the parameters of cardiac injury, higher doses of LY294002 (20 mg/kg) and YC-1 (2 mg/ kg) almost completely abolished the effects of CCK-8 preconditioning on biochemical parameters, and the effects in those groups were comparable to the IR injury group.

\section{Discussion}

In this present investigation, pharmacological preconditioning with CCK-8 was found to provide significant cardioprotection against IR-induced myocardial injury. There was a significant reduction in the release of cardiac injury markers, namely LDH-1, CK-MB, and cTnT, in the coronary effluent of ischemia-reperfusion injury model rats. Pharmacological preconditioning is an extrapolation of ischemic preconditioning, in which instead of short episodes of ischemia, a pharmacological agent is employed. ${ }^{27}$ Several pharmacological agents are known to exhibit pharmacological preconditioning-like effects. ${ }^{28}$ In the current study, cardioprotective effects were evaluated after $24 \mathrm{~h}$ of CCK- 8 administration. Therefore, the results suggest that CCK- 8 exerts late phase preconditioning on hearts. The results of the present study are in line with the results of a previous study showing the delayed phase of cardioprotective effects of CCK-8-induced pharmacological preconditioning. ${ }^{17}$

In this present study, along with the cardioprotective effects of CCK-8-induced preconditioning, we observed significant restoration of biochemical markers in IR-subjected rat hearts. In response to IR, there was a significant decrease in the expression of HIF- $1 \alpha$ and p-Akt and in $\mathrm{p}-\mathrm{GSK}-3 \beta / \mathrm{GSK}-3 \beta$ ratio. However, pharmacological preconditioning with CCK-8 led to significant restoration of HIF- $1 \alpha$ and $p$-Akt expression and of p-GSK-3 $\beta /$ GSK-3 $\beta$ ratio in the heart homogenates. The HIF- $1 \alpha$ is a hypoxiainducible transcriptional factor and its key role in ischemic $^{29}$ and remote preconditioning-induced cardioprotection has been previously demonstrated. ${ }^{30}$ The present finding of an increase in HIF- $1 \alpha$ level in response to CCK- 8 preconditioning is supported by previous studies showing that CCK-8 may increase the expression of HIF- $1 \alpha .{ }^{31}$ Furthermore, the present study demonstrated that the administration of a selective pharmacological inhibitor of HIF- $1 \alpha$, namely YC-1, significantly abrogated the cardioprotective effects of CCK-8-induced pharmacological preconditioning. Accordingly, it may be suggested that CCK-8-induced pharmacological preconditioning involves the activation of a HIF-1 $\alpha$-dependent signaling pathway.

The relationship between p-Akt and CCK-8-induced pharmacological preconditioning was also assessed in the current study. The results showed that CCK-8-induced pharmacological preconditioning was associated with restoration of $\mathrm{p}$-Akt expression and $\mathrm{p}-\mathrm{GSK}-3 \beta$ / GSK-3 $\beta$ ratio. Previous studies have described that PI3KAkt-GSK-3 $\beta$ constitutes an important signaling cascade mediating various biological effects, including ischemic, remote and pharmacological preconditioning-induced cardioprotection. ${ }^{32,33}$ PI3K leads to phosphorylation of Akt to increase its activity, ${ }^{34}$ and the phosphorylated form of Akt leads to phosphorylation of GSK-3 $\beta .{ }^{35}$ Of note, phosphorylation of GSK-3 $\beta$ leads to a decrease in its activity and, thus, a decrease in the $\mathrm{p}-\mathrm{GSK}-3 \beta / \mathrm{GSK}-3 \beta$ ratio indicates the potentiation of its activity. ${ }^{36}$

In this present study, pharmacological inhibition of PI3K using LY294002 led to significant attenuation 
of the cardioprotective actions of CCK-8-induced pharmacological preconditioning. Moreover, LY294002 abolished the restorative effects of CCK-8-induced pharmacological preconditioning on biochemical markers in the heart homogenates. To the best of our knowledge, this is the first study describing that the cardioprotective effects of CCK-8-induced pharmacological preconditioning are mediated through the PI3K-Akt-GSK-3 $\beta$ signaling pathway. Moreover, it is the first study describing that CCK-8-induced pharmacological preconditioning involves the activation of the HIF-1 $\alpha$-dependent signaling pathway. Previous studies have shown that hypoxia may trigger the activation of PI3K-Akt to increase the expression of HIF-1 $\alpha$, which may contribute to the resistance of the heart to ischemic injury. ${ }^{37,38}$ However, the present study did not delineate the precise sequence of the intracellular signaling pathway involving PI3K-Akt-GSK-3 $\beta$ and HIF- $1 \alpha$ in CCK-8-induced pharmacological preconditioning. Furthermore, roles of the RISK (reperfusion injury salvage kinase) and SAFE (survivor activating factor enhancement) signaling pathways in CCK-8-mediated protective effects in IR-induced myocardial injury have been reported. ${ }^{39}$ Accordingly, there are potential roles for these signaling pathways in CCK-8-mediated preconditioning effects.

Clinically, there are limited options to protect the heart from ischemic injury; therefore, CCK-8 may serve as a useful pharmacological tool to protect against ischemiareperfusion injury. In particular, CCK-8 may be useful in situations where myocardial ischemia is unavoidable, such as coronary artery balloon angioplasty, coronary artery bypass surgery, excision and transportation of a donor heart, and before exercise in patients with known demandinduced ischemia. Mechanistically, CCK-8 administration in the form of pharmacological preconditioning may trigger cardioprotective signaling, involving activation of the PI3K-Akt-GSK-3 $\beta$ pathway.

\section{Limitations and future directions}

The present study did not reveal the precise sequence of the HIF- $1 \alpha$ and PI3K-Akt-GSK-3 $\beta$ signaling pathways in CCK-8-induced pharmacological preconditioning. Thus, the role of the RISK and SAFE signaling pathways in CCK-8-mediated preconditioning effects warrant further investigation. Moreover, future studies should explore the clinical effects of CCK-8 preconditioning in patients suffering from ischemic heart diseases.

\section{Conclusions}

The findings of this study suggest that the molecular mechanisms participating in CCK-8-induced pharmacological preconditioning involve the HIF- $1 \alpha$, PI3K, Akt, and GSK-3 $\beta$ signaling pathway.

\section{ORCID iDs}

Yuan Cheng (D) https://orcid.org/0000-0002-4026-5607 Mengzuo Wu (D) https://orcid.org/0000-0003-2550-1007 Min Liu (D) https://orcid.org/0000-0002-4421-4540 Birong Zhou (D) https://orcid.org/0000-0002-9527-7453 Xianhe Lin (1) https://orcid.org/0000-0001-7899-4234

Bangning Wang (D) https://orcid.org/0000-0002-5165-0375

\section{References}

1. Urban PL, Cowley M, Goldberg S, et al. Intracoronary thrombolysis in acute myocardial infarction: Clinical course following successful myocardial reperfusion. Am Heart J. 1984;108(4 Pt 1):873-878. doi:10.1016/0002-8703(84)90448-4

2. Chandra R, Baumann FG, Goldman RA. Myocardial reperfusion, a cause of ischemic injury during cardiopulmonary bypass. Surgery. 1976;80(2):266-276. PMID:941098

3. Hausenloy DJ, Yellon DM. Ischaemic conditioning and reperfusion injury. Nat Rev Cardiol. 2016;13(4):193-209. doi:10.1038/nrcardio.2016.5

4. Benke K, Mátyás C, Sayour AA, et al. Pharmacological preconditioning with gemfibrozil preserves cardiac function after heart transplantation. Sci Rep. 2017;7(1):14232. doi:10.1038/s41598-017-14587-3

5. Luca MC, Liuni A, Muxel S, et al. Chronic pharmacological preconditioning against ischemia. Clin Hemorheol Microcirc. 2011;49(1-4): 287-293. doi:10.3233/CH-2011-1479

6. Goulton CS, Patten AR, Kerr JR, Kerr DS. Pharmacological preconditioning with GYKI 52466: A prophylactic approach to neuroprotection. Front Neurosci. 2010;4:54. doi:10.3389/fnins.2010.00054

7. Gabrielová E, Bartošíková L, Nečas J, Modrianský M. Cardioprotective effect of 2,3-dehydrosilybin preconditioning in isolated rat heart. Fitoterapia. 2019;132:12-21. doi:10.1016/j.fitote.2018.10.028

8. Chandra R, Liddle RA. Cholecystokinin. Curr Opin Endocrinol Diabetes Obes. 2007;14(1):63-67. doi:10.1097/MED.0b013e3280122850

9. Cawthon CR, de La Serre CB. The critical role of CCK in the regulation of food intake and diet-induced obesity. Peptides. 2021;2021:170492. doi:10.1016/j.peptides.2020.170492

10. Ochi R, Fujita N, Goto N, et al. Region-specific brain area reductions and increased cholecystokinin positive neurons in diabetic OLETF rats: Implication for anxiety-like behavior. J Physio/ Sci. 2020;70(1):42. doi:10.1186/s12576-020-00771-0

11. Roca-Lapirot O, Fossat P, Ma S, et al. Acquisition of analgesic properties by the cholecystokinin (CCK)/CCK2 receptor system within the amygdala in a persistent inflammatory pain condition. Pain. 2019; 160(2):345-357. doi:10.1097/j.pain.0000000000001408

12. Sadeghi $M$, Reisi $P$, Radahmadi $M$. The effects of CCK-8S on spatial memory and long-term potentiation at CA1 during induction of stress in rats. Iran J Basic Med Sci. 2017;20(12):1368-1376. doi:10. 22038/IJBMS.2017.9619

13. Zhang Y, Zhu J, Guo L, et al. Cholecystokinin protects mouse liver against ischemia and reperfusion injury. Int Immunopharmacol. 2017; 48:180-186. doi:10.1016/j.intimp.2017.03.028

14. Liu C, Chen $\mathrm{K}$, Wang $\mathrm{H}$, et al. Gastrin attenuates renal ischemia/reperfusion injury by a PI3K/Akt/Bad-mediated anti-apoptosis signaling. Front Pharmacol. 2020;11:540479. doi:10.3389/fphar.2020.540479

15. Dong X, Wang C, Zhang J, et al. Cholecystokinin expression in the development of postinfarction heart failure. Cell Physiol Biochem. 2017; 43(6):2479-2488. doi:10.1159/000484454

16. Wang C, Zhang C, Wu D, et al. Cholecystokinin octapeptide reduces myocardial fibrosis and improves cardiac remodeling in post myocardial infarction rats. Int JBiochem Cell Biol. 2020;125:105793. doi:10. 1016/j.biocel.2020.105793

17. $\mathrm{Li} \mathrm{H}, \mathrm{An} \mathrm{C}$. Exploring the role of neurogenic pathway-linked cholecystokinin release in remote preconditioning-induced cardioprotection. Acta Cir Bras. 2020;35(9):e202000906. doi:10.1590/s0102-86502 0200090000006

18. Jiang $\mathrm{L}$, Zeng $\mathrm{H}$, Ni L, et al. HIF-1a preconditioning potentiates antioxidant activity in ischemic injury: The role of sequential administration of dihydrotanshinone I and protocatechuic aldehyde in cardioprotection. Antioxid Redox Signal. 2019;31(3):227-242. doi:10.1089/ars.2018.7624

19. Yang $L, X i e P, W u J$, et al. Sevoflurane postconditioning improves myocardial mitochondrial respiratory function and reduces myocardial ischemia-reperfusion injury by up-regulating HIF-1. Am J Transl Res. 2016;8(10):4415-4424. PMID:27830025 
20. Rossello X, Riquelme JA, Davidson SM, Yellon DM. Role of PI3K in myocardial ischaemic preconditioning: Mapping pro-survival cascades at the trigger phase and at reperfusion. J Cell Mol Med. 2018;22(2): 926-935. doi:10.1111/jcmm.13394

21. Zi C, Zhang C, Yang Y, Ma J. Penehyclidine hydrochloride protects against anoxia/reoxygenation injury in cardiomyocytes through ATPsensitive potassium channels, and the Akt/GSK-3 $\beta$ and Akt/mTOR signaling pathways. Cell Biol Int. 2020;44(6):1353-1362. doi:10.1002/ cbin.11329

22. Fujiwara M, Izuishi K, Sano T, et al. Modulating effect of the PI3-kinase inhibitor LY294002 on cisplatin in human pancreatic cancer cells. J Exp Clin Cancer Res. 2008;27(1):76. doi:10.1186/1756-9966-27-76

23. Jiang $H$, Fan D, Zhou G, Li X, Deng H. Phosphatidylinositol 3-kinase inhibitor (LY294002) induces apoptosis of human nasopharyngeal carcinoma in vitro and in vivo. J Exp Clin Cancer Res. 2010;29(1):34. doi:10.1186/1756-9966-29-34

24. Yan J, Zhou B, Taheri S, Shi H. Differential effects of HIF-1 inhibition by YC-1 on the overall outcome and blood-brain barrier damage in a rat model of ischemic stroke. PLoS One. 2011;6(11):e27798. doi:10.1371/journal.pone.0027798

25. Bradic J, Milosavljevic I, Bolevich S, et al. Dipeptidyl peptidase 4 inhibitors attenuate cardiac ischaemia-reperfusion injury in rats with diabetes mellitus type 2. Clin Exp Pharmacol Physiol. 2020;48(4):575-584. doi:10.1111/1440-1681.13450

26. Watanabe M, Okada T. Langendorff perfusion method as an ex vivo model to evaluate heart function in rats. Methods Mol Biol. 2018;1816: 107-116. doi:10.1007/978-1-4939-8597-5_8

27. Ravindran S, Kurian GA. Preconditioning the rat heart with sodium thiosulfate preserved the mitochondria in response to ischemiareperfusion injury. J Bioenerg Biomembr. 2019;51(3):189-201. doi:10. 1007/s10863-019-09794-8

28. Naderi R, Imani A, Faghihi M. Phenylephrine produces late pharmacological preconditioning in the isolated rat heart. Eur J Pharmacol. 2010;627(1-3):203-208. doi:10.1016/j.ejphar.2009.10.052

29. Semenza GL. Hypoxia-inducible factor 1: Regulator of mitochondrial metabolism and mediator of ischemic preconditioning. Biochim Biophys Acta. 2011;1813(7):1263-1268. doi:10.1016/j.bbamcr.2010.08.006
30. Cai Z, Luo W, Zhan H, Semenza GL. Hypoxia-inducible factor 1 is required for remote ischemic preconditioning of the heart. Proc Natl Acad SciU S A. 2013;110(43):17462-17467. doi:10.1073/pnas.1317158110

31. Chao C, Goluszko E, Lee YT, et al. Constitutively active CCK2 receptor splice variant increases Src-dependent HIF-1 alpha expression and tumor growth. Oncogene. 2007;26(7):1013-1019. doi:10.1038/ sj.onc.1209862

32. Li J, Xuan W, Yan R, et al. Remote preconditioning provides potent cardioprotection via PI3K/Akt activation and is associated with nuclear accumulation of $\beta$-catenin. Clin Sci (Lond). 2011;120(10):451-462. doi:10.1042/CS20100466

33. Semenza GL. Hypoxia-inducible factor 1: Regulator of mitochondrial metabolism and mediator of ischemic preconditioning. Biochim Biophys Acta. 2011;1813(7):1263-1268. doi:10.1016/j.bbamcr.2010.08.006

34. Karar J, Maity A. PI3K/AKT/mTOR pathway in angiogenesis. Front Mol Neurosci. 2011;4:51. doi:10.3389/fnmol.2011.00051

35. Hermida MA, Dinesh Kumar J, Leslie NR. GSK3 and its interactions with the PI3K/AKT/mTOR signalling network. Adv Biol Regul. 2017;65: 5-15. doi:10.1016/j.jbior.2017.06.003

36. Patel P, Woodgett JR. Glycogen synthase kinase 3: A kinase for all pathways? Curr Top Dev Biol. 2017;123:277-302. doi:10.1016/bs.ctdb. 2016.11.011

37. Zhao R, Feng J, He G. Hypoxia increases Nrf2-induced HO-1 expression via the PI3K/Akt pathway. Front Biosci (Landmark Ed). 2016;21: 385-396. doi:10.2741/4395

38. Zhang SB, Liu TJ, Pu GH, Li BY, Gao XZ, Han XL. MicroRNA-374 exerts protective effects by inhibiting SP1 through activating the PI3K/Akt pathway in rat models of myocardial ischemia-reperfusion after sevoflurane preconditioning. Cell Physiol Biochem. 2018;46(4):1455-1470. doi:10.1159/000489186

39. Yang X, Yue R, Zhang J, et al. Gastrin protects against myocardial ischemia/reperfusion injury via activation of RISK (reperfusion injury salvage kinase) and SAFE (survivor activating factor enhancement) pathways. J Am Heart Assoc. 2018;7(14):e005171. doi:10.1161/JAHA.116.005171 